\title{
Translocation of intramural coronary artery in the arterial switch operation: Divide and conquer?
}

\author{
Tyson A. Fricke, MBBS, BMedSci, and Igor E. Konstantinov, MD, PhD, FRACS
}

\footnotetext{
From the Department of Cardiac Surgery, The Royal Children's Hospital, The University of Melbourne and the Murdoch Children's Research Institute, Melbourne, Victoria, Australia.

Disclosures: Authors have nothing to disclose with regard to commercial support

Received for publication Dec 22, 2017; accepted for publication Dec 28, 2017; available ahead of print Feb 4, 2018.

Address for reprints: Igor E. Konstantinov, MD, PhD, FRACS, The Royal Children's Hospital, Flemington Rd, Parkville, Victoria 3029, Australia (E-mail: igor.konstantinov@rch.org.au).

J Thorac Cardiovasc Surg 2018;155:e131-2

$0022-5223 / \$ 36.00$

Crown Copyright $(2) 2018$ Published by Elsevier Inc. on behalf of The American Association for Thoracic Surgery https://doi.org/10.1016/j.jtcvs.2017.12.108
}

Today, the operative mortality of the arterial switch operation (ASO) is expected to be less than $2 \%$ for children born with transposition of the great arteries and an intact interventricular septum. ${ }^{1}$ A single coronary artery is no longer a risk factor for death in most large-volume institutions. ${ }^{1,2}$ In contrast, an intramural coronary artery (IMCA) has been reported to increase operative mortality

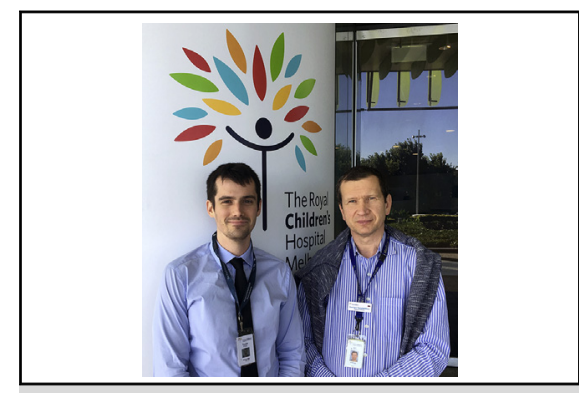

Tyson A. Fricke, MBBS, BMedSci, and Igor E. Konstantinov, MD, PhD, FRACS

Central Message

Transfer of the IMCA in the ASO can be challenging. However, excellent results can be achieved with reproducible techniques of coronary translocation.

See Article page e127.
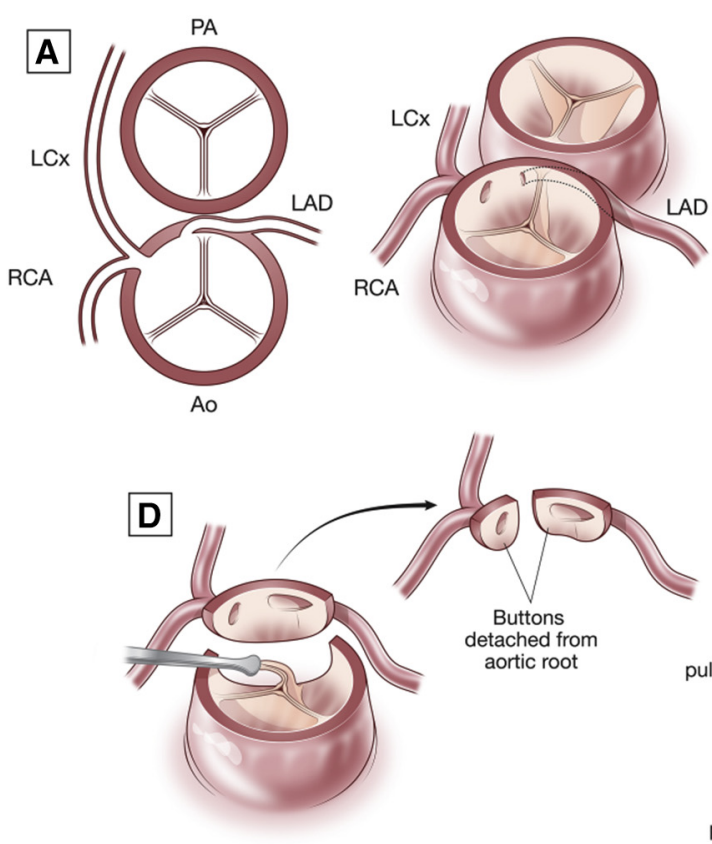

B
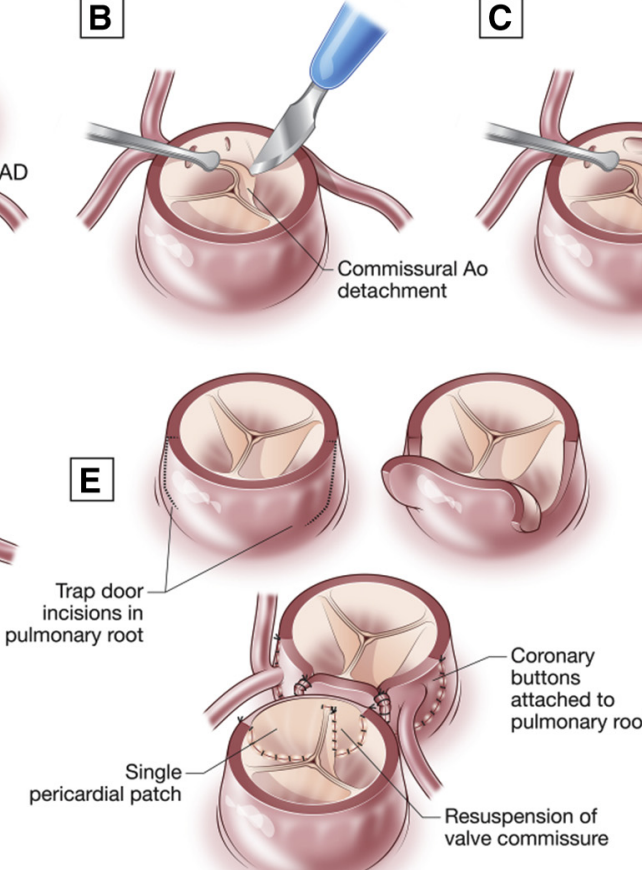
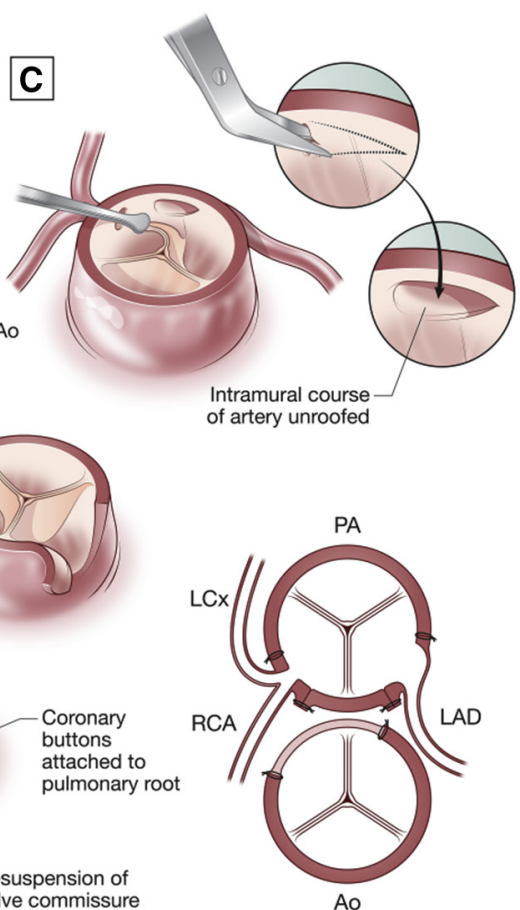

FIGURE 1. Surgical technique of Shaher 2a IMCA transfer. After identification of the intramural segment (A), detachment of the posterior commissure of the aortic (neopulmonary) valve is performed (B). The IMCA is unroofed (C). The coronary arteries are detached and transferred as 2 separate buttons using the trapdoor technique, the pulmonary artery is reconstructed with a single autologous pericardial patch, and the posterior neopulmonary valve commissure is reattached to the patch (D and E). RCA, Right coronary artery; $L C x$, left circumflex coronary artery; $P A$, pulmonary artery; $L A D$, left anterior descending artery; Ao, aorta. 
to more than $20 \%{ }^{3}$ In the current issue of the Journal, Ko and colleagues ${ }^{4}$ describe a technique for coronary translocation in a patient with an IMCA undergoing the ASO. They have previously applied this aortic sinus pouch technique for a patient with a single coronary artery undergoing the ASO. ${ }^{5}$ Such implantation of a single coronary button is an interesting approach to deal with an IMCA. In fact, the initial approach to IMCA transfer used by Roger Mee in the 1980s at the Royal Children's Hospital in Melbourne was also a single button transfer of both coronary arteries. ${ }^{6}$ Subsequently, a trapdoor technique for coronary translocation during the ASO, which was originally described by Brawn and $\mathrm{Mee},{ }^{7}$ has been modified for translocating IMCA by the Royal Children's Hospital team. ${ }^{6}$ Our technique involves detaching the posterior commissure of the neopulmonary valve if the coronaries arise in close proximity and unroofing the IMCA if the ostium is stenotic. The excised coronary button is then transferred to a medially based trapdoor (Figure 1). We have previously reported outcomes on 28 patients with IMCA operated with this technique with no deaths. ${ }^{8}$ The first 3 patients in our experience had coronary translocation as a single button facilitated by a pericardial hood. After a mean follow-up of 26.3 years (median, 26.6 years; range, 25.3-26.9 years), these 3 patients are alive and well. The subsequent 25 children with IMCA underwent ASO with individual translocation of both coronary arteries using the trapdoor technique. ${ }^{8}$ The latter 25 patients are all alive without the need for coronary reintervention after a mean 16.5 years (median, 17.7 years; range, 5.5-25.3 years). Thus, IMCA has not been a risk factor for mortality at our institution. ${ }^{1}$

The patient described by Ko and colleagues ${ }^{4}$ had Shaher 2a coronary anatomy, with the left anterior descending coming from sinus 1 and the circumflex coronary artery and the right coronary coming from sinus 2 . Of the 28 patients with IMCAs described in our recent article, 2 patients had this specific anatomy. ${ }^{8}$ Both patients underwent unroofing of the IMCA, division into 2 buttons, and a standard coronary translocation using our trapdoor technique. These patients are alive and asymptomatic 22 and 23 years after ASO.

It appears that the technique of Ko and colleagues ${ }^{4}$ is an elegant approach and might become a useful addition to the armamentarium of the congenital cardiac surgeon, provided that this technique results in good long-term outcomes. Time will tell.

\section{References}

1. Fricke TA, d'Udekem Y, Richardson M, Thuys C, Dronavalli M, Ramsay JM, et al. Outcomes of the arterial switch operation for transposition of the great arteries: 25 years of experience. Ann Thorac Surg. 2012;94:139-45.

2. Gerelli S, Pontailler M, Rochas B, Angeli E, Van Steenberghe M, Bonnet D, et al. Single coronary artery and neonatal arterial switch operation: early and long-term outcomes. Eur J Cardiothorac Surg. 2017;52:90-5.

3. Metton O, Calvaruso D, Gaudin R, Mussa S, Raisky O, Bonnet D, et al. Intramural coronary arteries and outcome of neonatal arterial switch operation. Eur J Cardiothorac Surg. 2010;37:1246-53.

4. Ko Y, Nomura K, Kinami H, Kawamura R. Aortic sinus pouch technique for transposition of the great arteries with intramural coronary artery. J Thorac Cardiovasc Surg. 2018;155:e127-9.

5. Ko Y, Nomura K, Nakao M. New coronary transfer technique for transposition of the great arteries with a single coronary artery. J Thorac Cardiovasc Surg. 2017; 153:1150-2.

6. Asou T, Karl TR, Pawade A, Mee RBB. Arterial switch: translocation of the intramural coronary artery. Ann Thorac Surg. 1994;57:461-5.

7. Brawn WJ, Mee RBB. Early results for anatomic correction of transposition of the great arteries and for double-outlet right ventricle with subpulmonary ventricular septal defect. J Thorac Cardiovasc Surg. 1988;95:230-8.

8. Fricke TA, Bulstra AE, Naimo PS, Bullock A, Robertson T, d'Udekem Y, et al. Excellent long-term outcomes of the arterial switch operation in patients with intramural coronary arteries. Ann Thorac Surg. 2016;101:725. 